\title{
CLIMATOLOGIA DO REGIME DE CHUVAS EM CAMPINA GRANDE/PB: MODELOS E VARIABILIDADES
}

\section{CLIMATOLOGY OF THE RAINFALL REGIME IN CAMPINA GRANDE/PB: MODELS AND VARIABILITY}

\section{CLIMATOLOGÍA DEL RÉGIMEN PLUVIAL EN CAMPINA GRANDE/PB: MODELOS Y VARIABILIDAD}

\author{
Hermes Alves de Almeida \\ Prof. Dr, Universidade Estadual da Paraíba (UEPB), Campina Grande, PB \\ hermes_almeida@uol.com.br \\ Emerson Galvani \\ Prof. Dr, Universidade de São Paulo (USP), Departamento de Geografia \\ egalvani@usp.br
}

\section{RESUMO}

O Semiárido nordestino é um recorte geográfico caracterizado pela elevada variabilidade no regime pluvial, sempre associada ao fenômeno da seca. Por isso, procurou-se estabelecer as principais características da climatologia da chuva da cidade de Campina Grande, PB, sendo essas determinações os objetivos principais. Dados mensais de chuvas, dos últimos 61 anos, foram cedidos pela AESA, PB, e analisados mediantes critérios da estatística climatológica. Utilizaram-se os métodos da anomalia da chuva e dos índices de seca meteorológica (anomalia da chuva, padronizado de precipitação modificado e decis), além de análises de dispersão. Os principais resultados indicaram que os modelos de regimes pluviais são assimétricos, irregulares e a estação chuvosa tem chance de ser seca. As oscilações mensais e anuais dos totais de chuvas observadas e as respectivas anomalias indicam que as dispersões são indicativas de variabilidade natural e não há indícios de mudança climática. Embora as secas sejam de difícil previsibilidade, os índices de secas meteorológica são eficazes para monitorar as diferentes categorias de seca. Recomenda-se o uso de dois ou mais índices e da comparação entre si a fim de estabelecer a tipologia da seca.

Palavras-chave: clima; precipitação pluvial; índices de secas; variabilidade climática; semiárido. 


\section{ABSTRACT}

The northeastern semiarid is a geographic feature characterized by high variability in the rainfall regime, always associated with the phenomenon of drought. Therefore, we sought to study the climatology of the pluvial regime in Campina Grande, PB, with these determinations being the main objectives. Monthly rainfall data for the last sixty-one years were provided by AESA, PB, and analyzed using climatologically statistics criteria. The methods of rainfall anomaly and meteorological drought indices (rain anomaly, modified precipitation standard and deciles) were used, in addition to dispersion analyses. The main results indicated that the models of rainfall regimes are asymmetrical, irregular, the temporal dispersions and the rainy season has a chance of being dry. The monthly and annual fluctuations of the observed rainfall totals and the respective anomalies indicate that the dispersions are indicative of natural variability and not of climate change. Although droughts are difficult to predict, meteorological drought indices are effective in monitoring different categories of drought. It is recommended the use of two or more indices and the comparison between them in order to establish the most real typology of the drought.

Keywords: climate; rainfall; drought indexes; climate variability; semiarid.

\section{RESUMEN}

El semiárido nororiental es un accidente geográfico caracterizado por una alta variabilidad en el régimen de lluvias, siempre asociado al fenómeno de la sequía. Por ello, se buscó estudiar la climatología del régimen pluvial en Campina Grande, PB, siendo estas determinaciones los principales objetivos. Los datos de precipitación mensual de los últimos sesenta y un años fueron proporcionados por AESA, PB y analizados utilizando criterios de estadísticas climatológicas. Se utilizaron los métodos de anomalía de lluvia e índices de sequía meteorológica (anomalía de lluvia, estándar de precipitación modificado y deciles), así como análisis de dispersión. Los principales resultados indicaron que los modelos de regímenes pluviales son asimétricos, irregulares y la temporada de lluvias tiene posibilidades de ser seca. Las fluctuaciones temporales de lluvia observadas y las respectivas anomalías indican que las dispersiones son indicativas de variabilidad natural y no de cambio climático. Aunque las sequías son difíciles de predecir, los índices de sequía meteorológicos son eficaces para monitorear diferentes categorías de sequías. Se recomienda el uso de dos o más índices y la comparación entre ellos para establecer la tipología más real de la sequía.

Palabras clave: clima; precipitaciones; índices de sequía; variabilidad climática; semi árido.

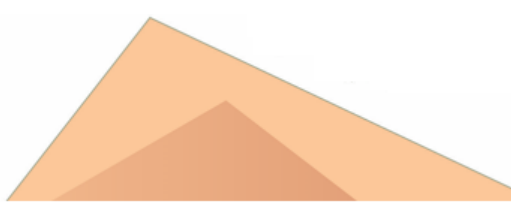




\section{INTRODUÇÃO}

As oscilações das condições meteorológicas são as principais responsáveis pela dinâmica ambiental, por exercerem influência direta tanto nos processos de ordem física quanto biológica, assim como na sociedade em geral.

Neste contexto, a precipitação pluvial se destaca como um dos elementos do clima mais importante, mas o que tem maior variabilidade espaço-temporal (FERREIRA et al., 2018; DIAS e PENNER, 2021), podendo ser o mais influenciado num cenário de mudança climática.

As variabilidades temporais e espaciais dos regimes pluviais são características marcantes no Semiárido nordestino, não somente nos totais mensais ou anuais, mas na quantidade, distribuição e duração da estação chuvosa (ALMEIDA e FARIAS, 2015).

Os principais mecanismos dinâmicos indutores de chuvas no nordeste brasileiro e, em especial, no recorte geográfico paraibano resultam de acoplamentos de vários sistemas atmosféricos, com predominância para os da Zona de Convergência Intertropical (ZCIT), influencia o regime pluvial na parte setentrional no nordeste e na região norte do Brasil (NOBRE e MOLION, 1988; UVO, 1989).

Nos anos de seca, a ITCZ, que é o principal mecanismo indutor de chuva no Semiárido (MOLION e BERNARDO, 2002), fica bloqueada mais ao norte de sua posição normal e no final do verão e início do outono, ela se posiciona mais ao sul, que coincide, portanto, com a estação das chuvas (REBOITA et al., 2010).

O regime pluvial no leste do Nordeste recebe uma contribuição significativa de chuva, nos meses de maio a julho, que advém dos distúrbios ondulatórios de leste, denominado de Onda de Leste (OL), que se propagam do Oceano Atlântico em direção ao continente, durante o outono/inverno (CHAN, 1990; KOUADIO et al., 2012). Esse sistema pode provocar eventos extremos de chuva, com alagamentos e deslizamentos de encostas (MACHADO et al., 2012).

Os Vórtices Ciclônicos de Altos Níveis (VCAN) correm na atmosfera superior, são perceptíveis nas cartas sinóticas de $200 \mathrm{hPa}$ e favorecem a ocorrência de chuvas em várias regiões brasileiras e, em particular, no nordeste. O VCAN é uma 
circulação ciclônica fechada que se forma, preferencialmente, sobre o Oceano Atlântico Tropical Sul e se desloca para Oeste na primavera, outono e verão (GAN e KOUSKY, 1986; COUTINHO, 2010).

Analisar as oscilações de séries pluviais, combinadas ou não com outros elementos do clima, permite detectar periodicidades que são fundamentais para planejar inúmeras atividades agrícolas, econômicas, sociais, dentre outras (SILVA et al., 2005).

As cidades, em geral, despertam mais atenção aos eventos extremos de chuvas, especialmente, porque são espaços onde se concentram áreas mais suscetíveis aos impactos mais severos, tais como: enchentes, deslizamentos de terra e perdas de vida.

A seca é um fenômeno meteorológico extremo e complexo, afeta drasticamente uma região, por provocar danos ambientais, econômicos e sociais graves, frequentemente, agravada pelas ações antrópicas.

A seca é uma característica temporária do tempo, definida, a priori, quando os totais de chuva são inferiores aos valores referenciais, na sua maioria, a média climatológica. No Semiárido nordestino, as secas fazem parte da variabilidade natural do clima, que ocorreram no passado e estão ocorrendo no presente e que poderão ser intensificadas, diante das projeções de mudanças climáticas (MARENGO et al., 2016).

A identificação de eventos extremos de chuvas pode ser caracterizada, utilizando-se diferentes técnicas estatísticas, com destaque para os trabalhos desenvolvidos por McKee et al. (1993), Coelho et al. (2015) e outros.

As secas são, conceitualmente, descritas em quatro tipos: meteorológica, hidrológica, agrícola e socioeconômica (FERNANDES et al., 2009). Qualquer tipo de seca inicia-se pela meteorológica que resulta da diminuição da pluviosidade. Se essa condição persistir, com o tempo, vai ocasionar os demais tipos de secas, embora possa ocorrer a seca hidrológica e não acontecer à agrícola.

A combinação das três secas mencionadas, por exemplo, tem-se a seca socioeconômica, a qual se relaciona com a oferta e demanda de bens, tais como a água, alimentos e energia, que se manifesta sequencialmente após a seca meteorológica.

A compreensão das características de eventos extremos de chuva (frequência, intensidade, duração) requer informações atuais e históricas das condições 
meteorológicas (curto prazo) ou climatológicas (médio prazo), ambos integram a variabilidade climática.

Neste contexto, os objetivos principais deste trabalho foram o de estabelecer as principais características dos modelos estatísticos da climatologia dos regimes pluvial na cidade de Campina Grande, PB.

\section{MATERIAIS E MÉTODOS}

A cidade de Campina Grande (Figura 1), localiza-se na região geográfica intermediária de Campina Grande, PB, latitude 7º13'50" S, longitude 35 52' 52" W e altitude de $550 \mathrm{~m}$.

Figura 1 - Vista aérea da parte central da cidade de Campina Grande, PB

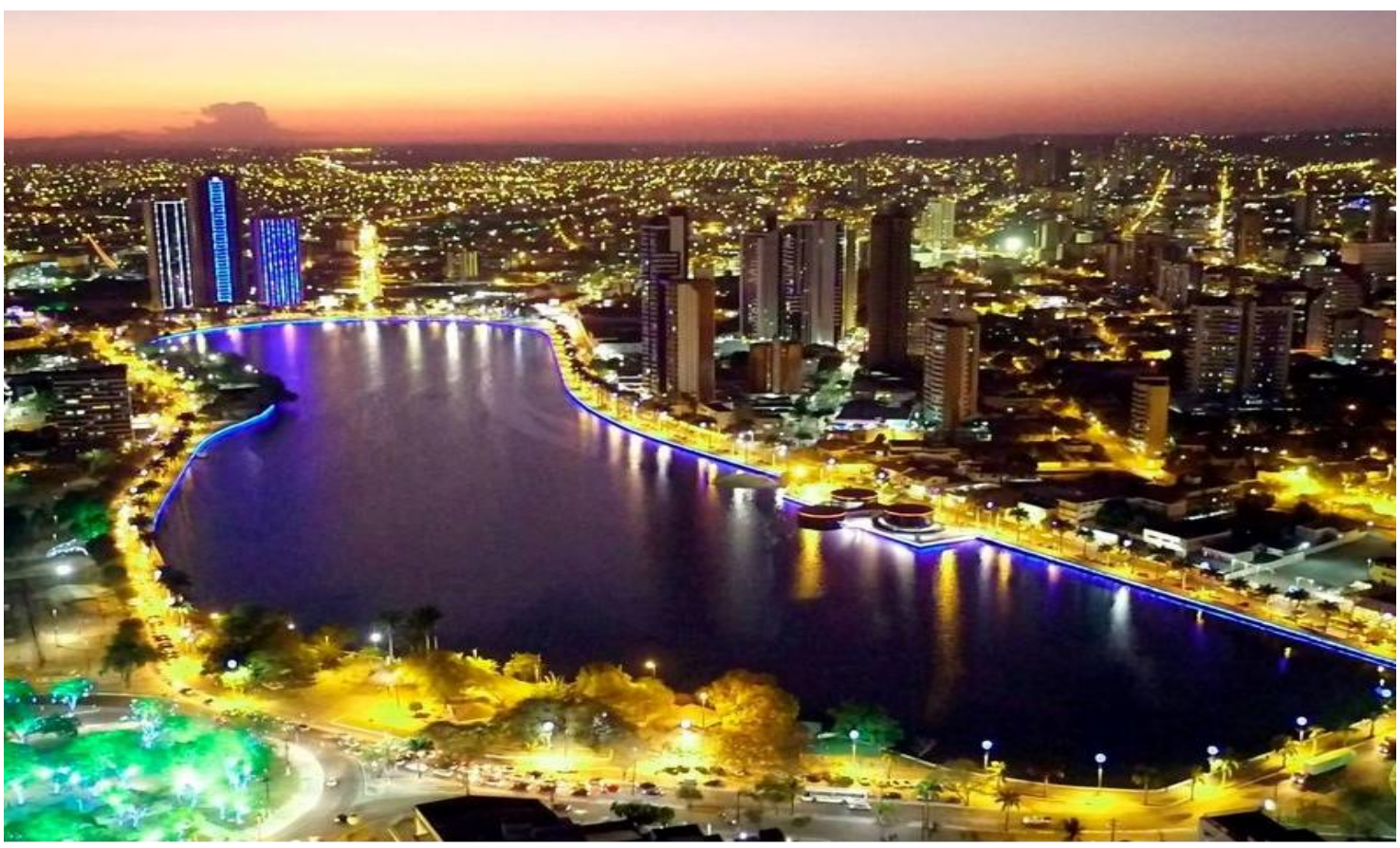

Fonte: https://www.oimenu.com.br/cardapio-digital-campina-grande-pb, disponível em 16.07.2021

O clima, de acordo com a classificação climática de Köppen, é do tipo tropical chuvoso (A), megatérmico, com temperatura média do mês mais frio maior que $18{ }^{\circ} \mathrm{C}$ e 
média anual de precipitação pluvial superior a $700 \mathrm{~mm}$ e estação chuvosa entre outono e inverno.

As séries de dados mensais e anuais de chuvas da cidade de Campina Grande foram extraídas dos arquivos da SUDENE e/ou cedidas pela Agência Executiva de Gestão das Águas (AESA), correspondente ao período: 01.01.1911 a 31.12.2020, agrupando-as seguindo-se uma sequência cronológica.

Os modelos da climatologia das chuvas foram estabelecidos, utilizando-se os critérios e métodos da estatística descritiva, determinando-se as medidas de tendência central (média e mediana), de dispersão (desvio padrão) e os parâmetros da distribuição de frequência (histogramas e polígonos de frequência).

Na comparação gráfica, verificou-se que as médias mensais e anuais de chuvas diferem das medianas e, por isso, os respectivos modelos de distribuição são assimétricos e, portanto, utilizou-se a mediana e não a média aritmética simples.

As oscilações anuais e na estação chuvosa foram determinadas pelas diferenças entre os valores observados, em cada escala temporal, e a mediana esperada da série, denominando-as por anomalias da chuva (AC) e calculadas pela expressão:

\section{$A C(\mathrm{~mm})=$ Ovalor da chuva observada (no mês ou ano $)$ - mediana da série}

Para averiguar se as os totais de chuvas observados anualmente e as ACs indicam variabilidades naturais, eventos extremos ou indícios de mudança climática (no regime pluvial), compararam-se os valores da chuva observados (no ano e na estação chuvosa) com os respectivos desvios padrão ( $\pm \mathrm{DP})$ das séries, mediante as equações:

\section{Chuva observada $(\mathrm{mm}) \pm \mathrm{DP}$ da série $(\mathrm{mm})$}

\section{Anomalia da chuva $(A C-m m) \pm D P$ da série $(m m)$}

Para monitorar as categorias/tipologias das secas meteorológicas, para os totais de chuvas observados, aplicaram-se os respectivos procedimentos metodológicos 
dos métodos, através dos índices: de anomalia da chuva (IAC), padronizado de precipitação modificado (SPIM) e dos Decis, descritos nas equações:

a) Índice de anomalia da chuva (IAC):

- O IAC foi determinado pela diferença entre cada valore observado e a média esperada. Nessa contabilidade, primeiramente, fez-se a ordenação das diferenças algébricas positivas das negativas (AC), ordenando-se, cronologicamente, as anomalias positivas das negativas, calculando-se pelas equações:

$$
\begin{aligned}
& I A C=3 \times\left[\frac{(\text { Pobs }- \text { Pmédia })}{(\bar{M}-\text { Pmédia })}\right], \text { para anomalias positivas; } \\
& I A C=-3 \times\left[\frac{(\text { Pobs }- \text { Pmédia })}{(\bar{X}-\text { Pmédia })}\right], \text { para anomalias negativas. }
\end{aligned}
$$

Sendo:

Pobs= precipitação pluvial observada $(\mathrm{mm})$

Pmédia $=$ precipitação pluvial média da série $(\mathrm{mm})$;

$\bar{M}=$ média dos dez maiores valores de precipitações observadas (mm)

$\bar{X}=$ média dos dez menores valores de precipitações observadas $(\mathrm{mm})$

- De posse dos valores do IAC, adotaram-se as tipologias descritas por Araújo et al., (2009), com algumas modificações, para enquadrar as respectivas categorias de secas, conforme mostra a Tabela 1.

Tabela 1 - Índice de anomalia da chuva (IAC) e suas respectivas categorias de seca, conforme tipologia proposta por Araújo et al., (2009)

\begin{tabular}{lr}
\hline \multicolumn{1}{c}{ Índice de Anomalia da Chuva (IAC) } & Categorias Umidade/Seca \\
\hline IAC $>=4,0$ & Extremamente úmida \\
$2,0=<$ IAC $<4,0$ & Muito úmida \\
$0,0=<$ IAC $<2,0$ & Úmida \\
$-2,0=<$ IAC $<0,0$ & Seca \\
$-4,0=<$ IAC $<-2,0$ & Muito seca \\
IAC $<-4,0$ & Extremamente Seca \\
\hline
\end{tabular}


b) Índice padronizado de precipitação modificado (SPIM):

- O método do Índice padronizado de precipitação (SPI) quantifica o déficit de precipitação, para múltiplas escalas de tempo, cujos procedimentos metodológicos foram desenvolvidos por McKee et al., (1993). Em virtude da assimetria do modelo de chuva, Almeida e Silva (2008) modificaram o método original, substituindo-se a média, pela mediana (med), que passou a ser denominado de índice padronizado da precipitação modificado (SPIM) e calculado pela equação:

$\mathrm{SPIM}=\frac{(\text { Pobservada-Med })}{D P}$

Sendo: Pobservada $=$ precipitação pluvial observada, em mm;

Med = mediana da precipitação pluvial (da série), em mm;

$\mathrm{DP}=$ desvio padrão da média da chuva (da série), em mm.

- As categorias de secas foram estabelecidas a partir dos SPIMs, adotando-se os critérios de McKee et al., (1993) e descritas na Tabela 2.

Tabela 2 - Índice Padronizado de Precipitação Modificado (SPIM) e categorias de umidade

\begin{tabular}{|c|c|}
\hline SPIM & Categorias de umidade/seca \\
\hline$\geq 2,00$ & Extremamente Úmido \\
\hline $1,50 \rightarrow 1,99$ & Muito úmido \\
\hline $1,00 \rightarrow 1,49$ & Moderadamente Úmido \\
\hline $0,99 \rightarrow-0,99$ & Próximo ao normal \\
\hline$-1,00 \rightarrow-1,49$ & Moderadamente Seco \\
\hline$-1,50 \rightarrow-1,99$ & Muito Seco \\
\hline$\leq-2,00$ & Extremamente Seco \\
\hline
\end{tabular}

c) Método dos Decis:

- Esse método consistiu em agrupar em décimos (decis) por ordem crescente, do primeiro, segundo, até o décimo decis. Com base nos decis, foram determinadas as probabilidades empíricas (Pr), ordenando-se cronologicamente os dados de chuvas, nas escalas estudadas (Tabela 3 ). 
Tabela 3 - Decis, probabilidade e categorias de umidade/seca, propostas por Fernandes et al., (2009)

\begin{tabular}{lrr}
\hline \multicolumn{1}{c}{ Decis } & Probabilidades (Pr) & Categorias umidade/seca \\
\hline $8-10$ & $\operatorname{Pr}>=80 \%$ & Extremamente úmido \\
$6-8$ & $60 \%=<\operatorname{Pr}<80 \%$ & Muito úmido \\
$4-6$ & $40 \%=<\operatorname{Pr}<60 \%$ & Moderadamente úmido \\
$2-4$ & $20 \%=<\operatorname{Pr}<40 \%$ & Muito seco \\
$1-2$ & $\operatorname{Pr}<20 \%$ & Extremamente seco \\
\hline
\end{tabular}

\section{RESULTADOS E DISCUSSÃO}

Nas últimas décadas, estudos científicos priorizam na temática da variabilidade do regime pluvial e aos impactos de alguns eventos extremos, por afetar diretamente o meio ambiente e a sociedade humana. Por isso, faz-se necessário estabelecer as principais características do regime pluvial local e averiguar se as dispersões são ou não indícios de mudança climática, alusão essa sempre citada nos relatórios do Painel Intergovernamental sobre Mudanças Climáticas (IPCC).

A Figura 2 mostra os modelos de distribuição de chuvas, para a cidade de Campina Grande, PB, referentes às médias mensais das medias, medianas e desvios padrão (DP). Observa-se que, os valores das médias mensais da precipitação são extremamente irregulares ao longo do ano, cujos desvios padrão superam as médias aritméticas, dos meses de setembro a fevereiro.

Figura 2 - Modelos estatísticos da distribuição das médias mensais da média, mediana e desvio padrão da chuva. Campina Grande, PB. Período: de janeiro de 2011 a dezembro de 2020

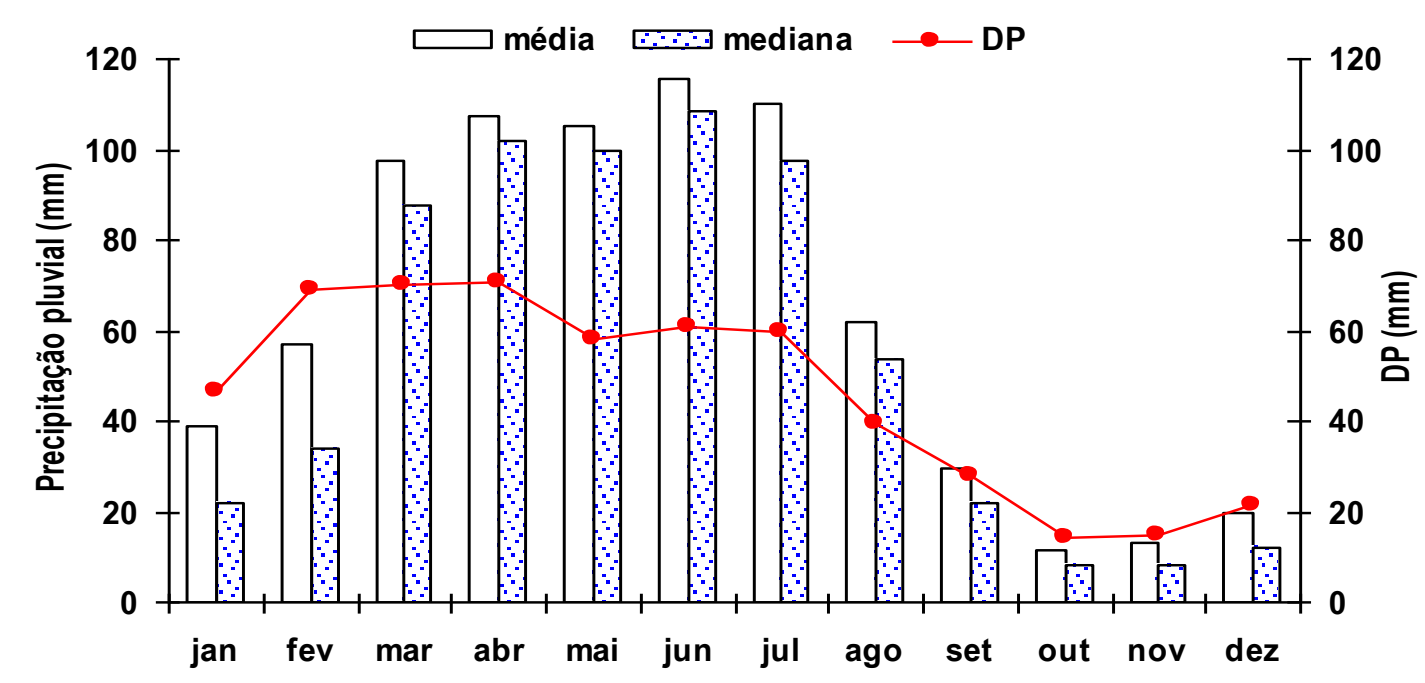


Os valores dos desvios padrão das médias são superiores aos das médias nos meses de julho a dezembro. Observa-se, ainda, Figura 2, que nos meses menos chuvosos, os valores das dispersões são relativamente maiores, ou seja, a variabilidade é inversamente proporcional ao valor mediano.

$\mathrm{Na}$ análise gráfica, verifica-se que as médias mensais das médias são diferentes e superiores aos valores medianos. Isso indica, portanto, que o modelo de distribuição de chuva é assimétrico e o coeficiente de assimetria de Person é positivo. Essa assimetria indica que não se deve usar a média, mesmo sendo a medida de tendência central mais usada, por não ser o valor mais provável de ocorrer. Por isso, concorda-se em recomendar o uso da mediana, em vez da média, o que corrobora com os resultados encontrados para outras localidades por Oliveira, Nóbrega e Almeida (2012), Almeida e Cabral Júnior (2014) e Almeida e Farias (2015).

Como o modelo mensal de distribuição de chuva é assimétrico, a curta estação chuvosa foi estabelecida pela sequência dos maiores valores mediana (Figura 3). Mesmo assim, constata-se a existência de uma elevada variabilidade, nesse curto período chuvoso (de março a julho), cuja dispersão média, equivale a cerca de 60,0 \% do valor esperado.

Figura 3 - Modelos estatísticos das medianas, desvios padrão e dispersão da chuva, nos meses da estação chuvosa. Campina Grande, PB, no período: janeiro de 2011 a dezembro de 2020

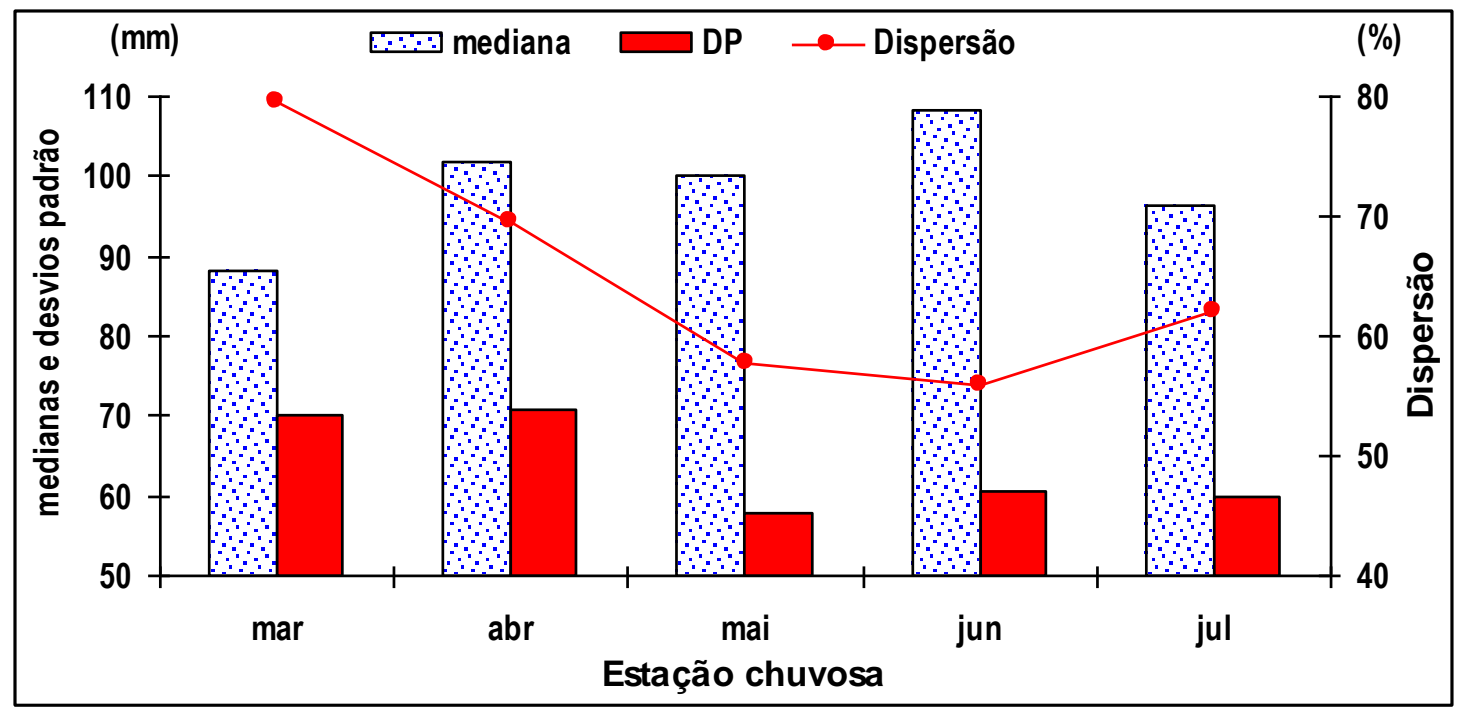


As elevadas dispersões mensais mostram, entretanto, que há chances da estação chuvosa ser seca. Essas condições são geralmente atribuídas como mudança climática, quando na realidade essas oscilações, nesses meses, indicam variabilidade natural do regime de chuvas.

As oscilações espaciais e temporais da chuva são características inerentes do tempo e do clima. Quando a descrição for do clima, a sequência cronológica do tempo é de trinta anos ou mais, ou seja, a média climatológica.

Se o clima é descrito por uma média e essa medida, associa-se ao desvio padrão, comparou-se o valor da chuva observado anualmente, com a média climatológica \pm o desvio padrão (Figura 4).

Fazendo-se essa comparação, observa-se (Figura 4) que a maioria dos sessenta e um dados de chuva observados, oscilou entre a média + o desvio padrão e entre a média- o desvio padrão. Constatou-se que, em apenas alguns anos, os totais de chuvas foram acima ou abaixo da média \pm DP, em 11,4 e 4,9\% dos anos, respectivamente.

As oscilações que ultrapassam as médias \pm os desvios padrão são consideradas como eventos extremos, embora a priori, elas sejam inerentes as características de variabilidade do elemento chuva, cuja hierarquização enquadra-se como flutuação climática do regime pluvial.

Figura 4 - Totais anuais de chuva observada comparados com a média climatológica \pm desvio padrão (DP), na cidade de Campina Grande, PB

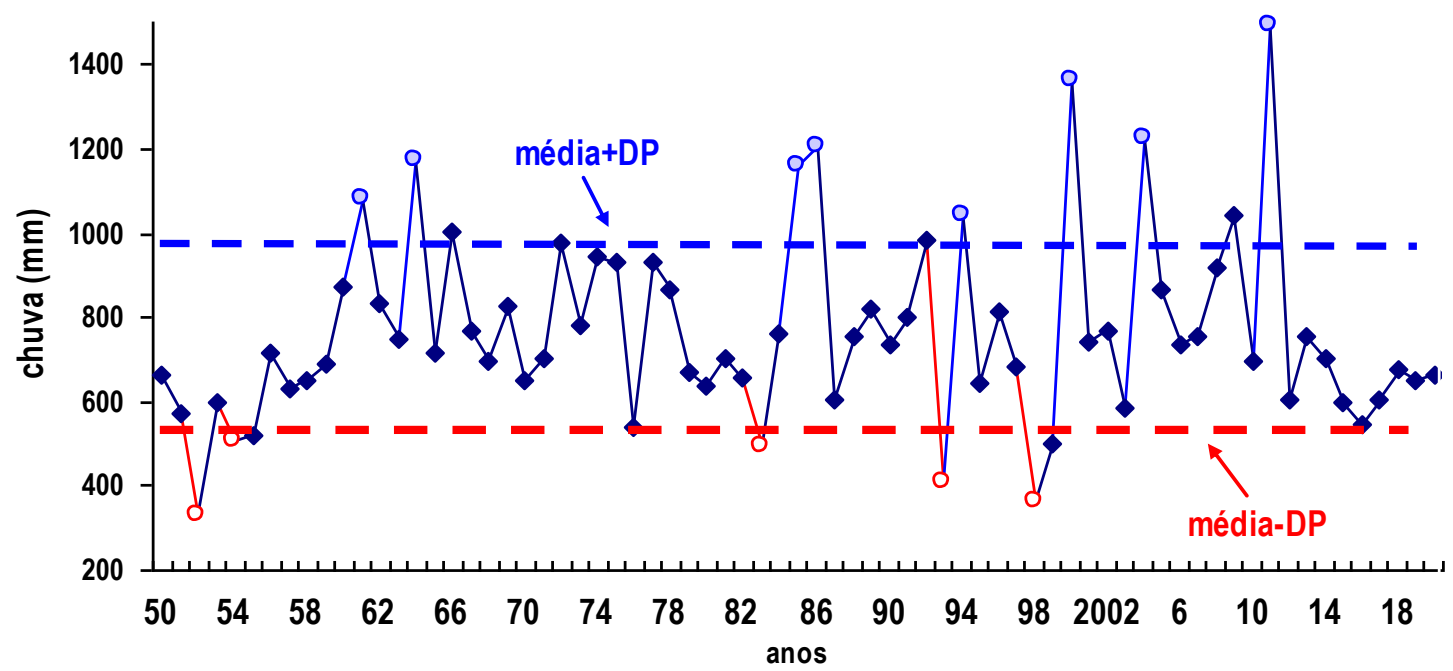


A sequência ano a ano dos totais de chuvas observados mostram uma elevada variabilidade natural nesse quantitativo. Isso mostra, portanto, as elevadas dispersões associadas a esse elemento, nessa escala, o que corrobora com Almeida e Marques (2021), a precipitação pluvial é o elemento de com maior variação em qualquer região.

Os extremos observados da chuva (acima ou abaixo da média \pm DP), ocorreram em alguns anos não devem ser creditados, confundidas e muito menos, ainda, descritos como mudança climática, Embora para Marengo (2008) essa condição tem como consequência a frequência de eventos extremos de chuva, especialmente, na intensidade e duração de períodos secos. Concorda-se com Junges e Massoni (2018) e Pina, Silva e Oliveira Júnior, (2010) que o tema mudança climática é complexo e torna difícil separar os elementos controversos dos não controversos.

Por outro lado, há necessidade da modelagem estatística, como um critério científico, a fim de estabelecer as características principais da variabilidade temporal da chuva observada. A anomalia da chuva é uma técnica que consiste comparar, o valor de chuva observado em relação ao esperado (mediana). As anomalias dos totais de chuvas observados, anualmente e na estação chuvosa, comparadas com os valores das médias climatológicas \pm os desvios padrão, são apresentadas nas Figuras 5 e 6.

Figura 5 - Anomalias da chuva (AC) anual observada, comparadas com a média climatológica \pm desvio padrão (DP), na cidade de Campina Grande, PB.

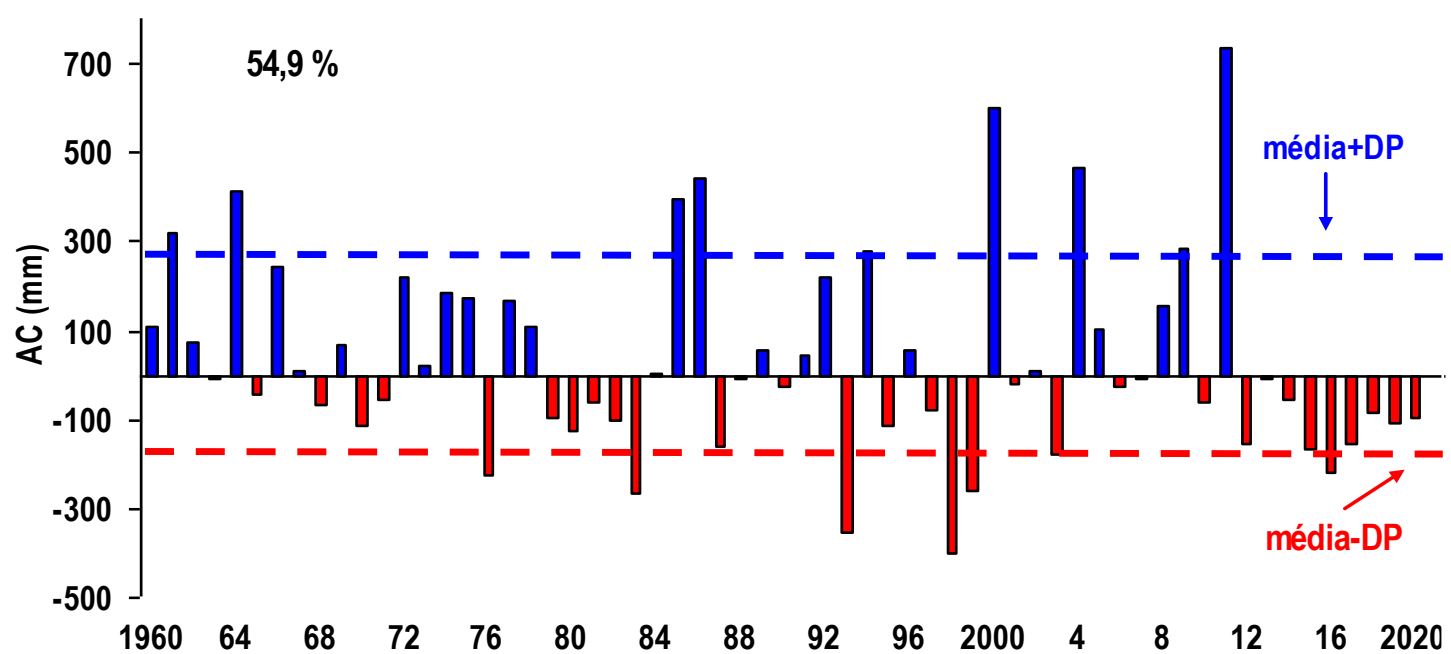


Os modelos de dispersões entre os totais observados e o esperado (mediano) revelam irregularidade no modelo de distribuição da chuva, representadas pelas anomalias negativas, totais de chuvas observados abaixo do esperado (retângulos vermelhos), e positivas, precipitações acima do esperado (retângulos azuis).

Figura 6 - Anomalias da chuva (AC) observada, na estação chuvosa, comparadas com a média climatológica \pm o desvio padrão (DP), na cidade de Campina Grande, PB.

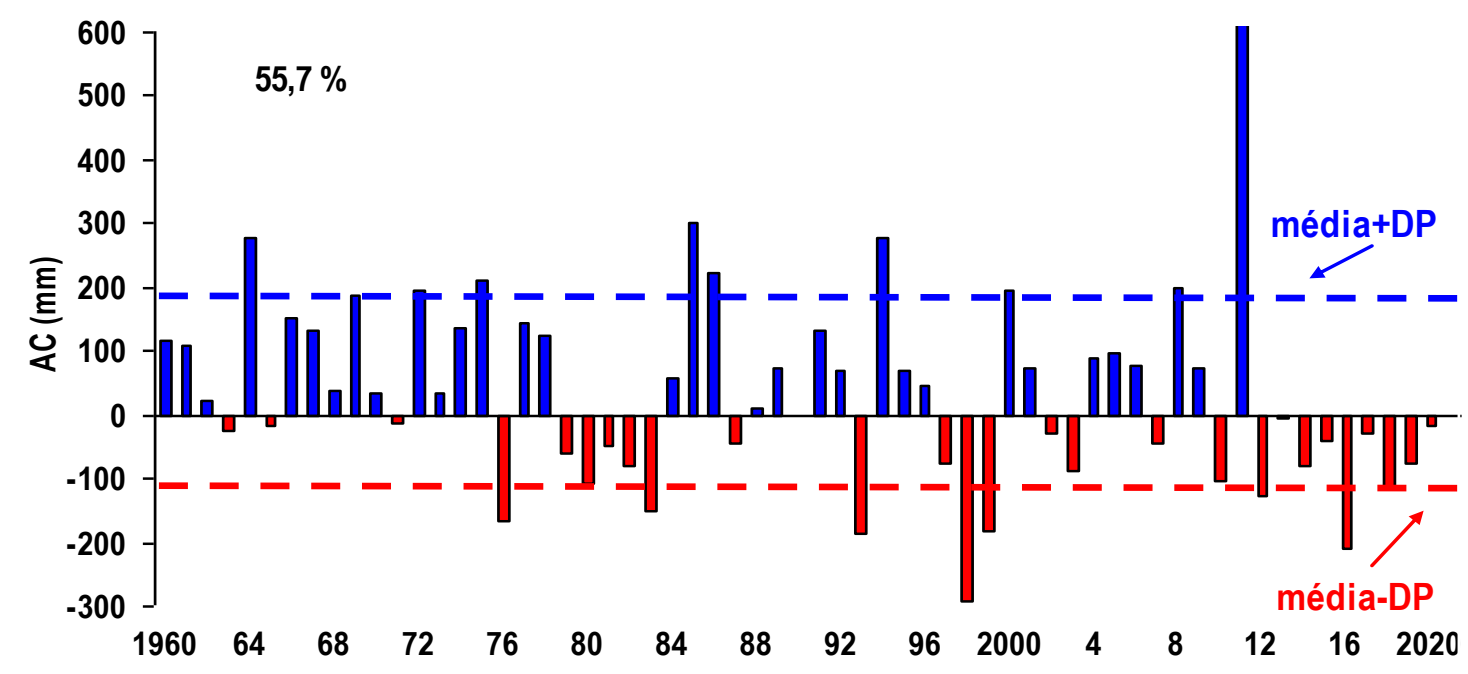

Os somatórios das frequências das ACs negativas, referentes aos números de anos (Figura 5) e na estação chuvosa (Figura 6), constatam-se percentuais de 55,1 e 44,3 $\%$, respectivamente. Contrariamente, os complementos das frequências com ACs positivas foram de 54,9 e $55,7 \%$.

Os resultados de AC anuais são compatíveis e corroboram com os encontrados por Almeida e Ramos (2020), para a cidade de Sumé, no cariri paraibano. No entanto, difere das ACs negativas, especificamente, na estação chuvosa, porque a chuva se concentra no outono (março a maio) e a de Campina Grande, os meses mais chuvosos são os de inverno.

Outra característica importante nos modelos de variabilidade da chuva (Figuras 5 e 6), no período estudado, é quando se compara os módulos das anomalias da chuva com média climatológica \pm o DP. Observa-se, nas referidas figuras, que mais de $75 \%$ dos anos as oscilações foram, respectivamente, menores e maiores que a média climatológica + o desvio e a média climatológica menos o desvio padrão. 
Em apenas 14,7 \% dos anos analisados e em 12,3\%, dos meses das estações chuvosos, os totais de chuvas foram maiores ou menores que a média climatológica \pm DP, ou seja, em mais de 85,0 \% ficam dentro do intervalo da média \pm DP. Isso mostra, portanto, que as oscilações apresentadas indicam a existência de uma variabilidade natural da climatologia da chuva, sem indícios de mudança no regime pluvial e muito menos ainda de mudança climática, até porque essas oscilações além de serem de curto prazo não são estatisticamente significativas.

A seca é um fenômeno meteorológico que afeta drasticamente uma determinada região, por provocar danos econômicos e sociais graves. Essa característica temporária do Tempo é descrita, a priori, quando os totais de chuvas, mensais ou num certo período, são menores que os esperados. Essa condição pode ser avaliada pelos índices: de anomalia da chuva, padronizado de precipitação modificado e decis, cujas frequências relativas, para cada tipologia da seca especificada em cada método, são mostradas, respectivamente, nas Figuras 7 e 8.

Como não há um conceito universal para definir a seca, as descrições das categorias de secas e/ou de umidade, em qualquer método de monitoramento, diferem entre si. As anomalias negativas da chuva anualmente (Figura 5) indicam os déficits pluviais, além disso, quanto mais negativo for, maior será o déficit.

Figura 7 - Frequências relativa de anos, com categorias de umidade/seca meteorológicas, estabelecidas pelo método do índice de anomalia da chuva. Campina Grande, PB, no período: 1960 a 2020.

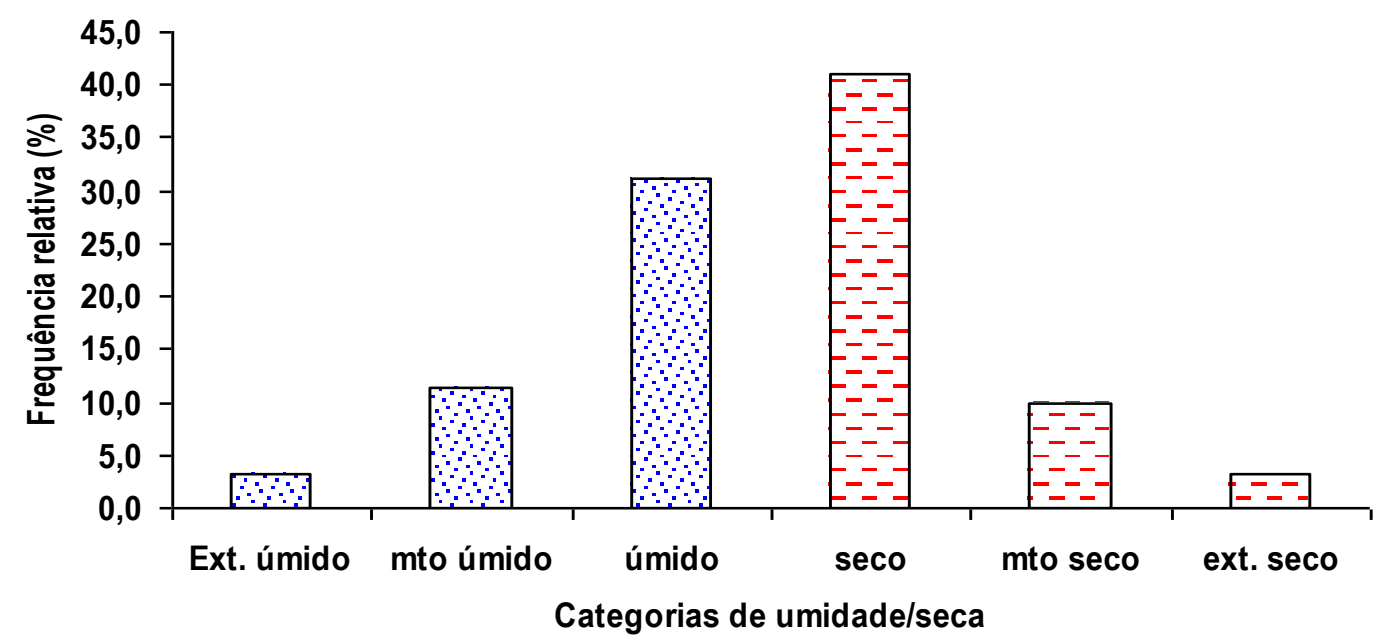


Figura 8 - Frequências relativa de anos, com categorias de umidade/seca meteorológicas, estabelecidas pelo método do índice padronizado de precipitação modificado. Campina Grande, PB, no período: 1960 a 2020.

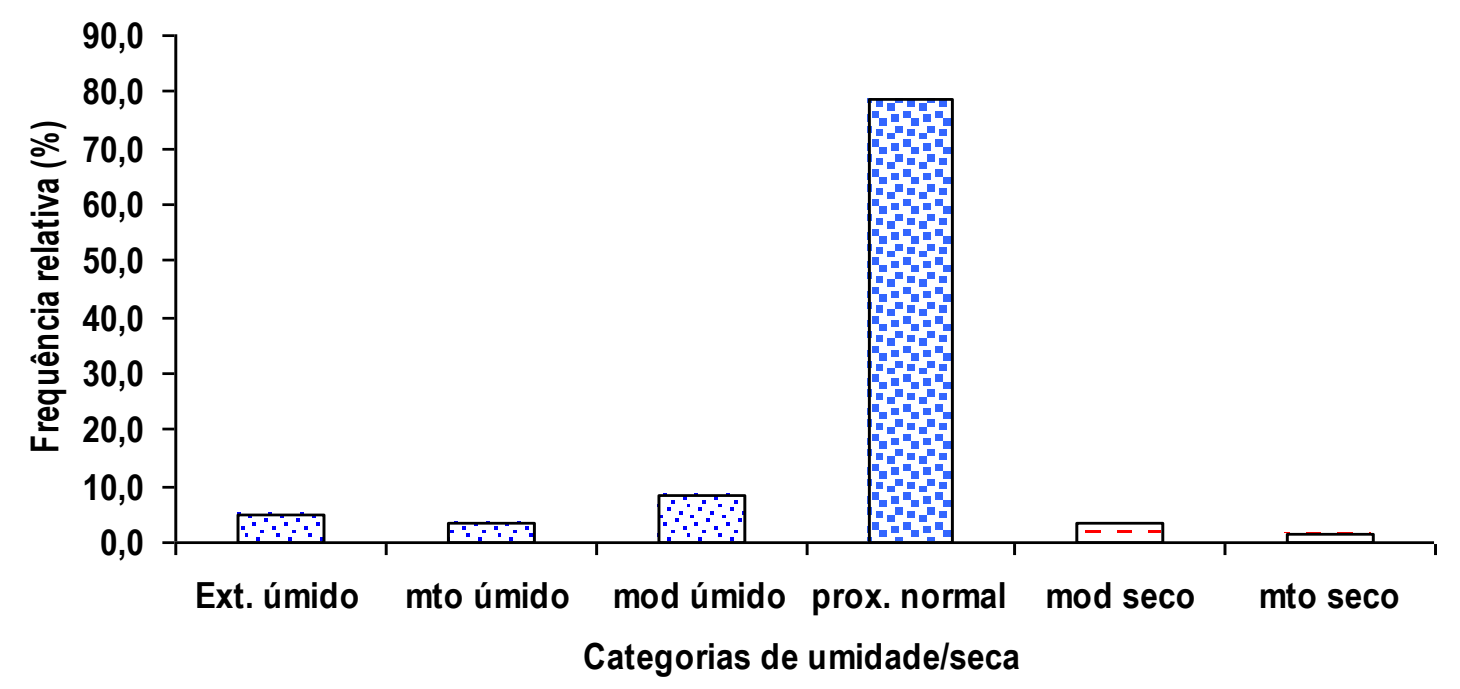

Na escala anual, o mês com o primeiro déficit, há prenúncio de início de uma seca meteorológica e a depender, da sua continuidade, fica caracterizada a seca. Neste contexto, corrobora-se com Palmer (1965), que o intervalo de tempo, geralmente é da ordem de meses, durante o qual a precipitação pluvial, ou o abastecimento hídrico, seja menor que o valor "climatologicamente" esperado.

As frequências relativas dos índices de anomalia da chuva (Figura 7) mostram que 57,4 \% dos anos, ocorreram secas, nas categorias, enquadradas como de extremamente úmido a úmido e de $42,6 \%$ de seco a extremamente seco.

Embora a categoria seca tenha sido repetida em vinte cinco anos, da série de sessenta e um anos, o equivalente a $41,0 \%$, enquanto que, as categorias extremas (extremamente úmida ou extremamente seca), ocorreram com uma frequência muito pequena (em apenas em dois anos).

Análises comparativas das categorias de umidade/seca da Figura 7, estabelecidas pelo índice de anomalia da chuva, com as do padronizado de precipitação modificado (Figura 8), mesmo com tipologias distintas, verifica-se que há predominância da categoria próxima ao normal, com frequência de 78,7 \% dos anos e os 21,3\%, restantes foram para outras categorias de secas. 
Na comparação dos dois métodos é visível as diferenças das frequências nas tipologias; no índice de anomalia da chuva (Figura 7) as categorias úmidas e secas são predominantes, totalizando-se $71,1 \%$ da frequência, contra 78,7 \% na próxima ao normal, no método padronizado de precipitação modificado. Apesar de não ter sido observada tendência nos dados de chuvas, foi possível observar eventos extremos e aleatoriedade nos dados.

As desigualdades nas categorias de umidade/seca se devem, em parte, aos procedimentos utilizados em cada método. No primeiro, utilizou-se a média aritmética, mesmo não sendo a medida de tendência central recomendada nos modelos assimétricos. O segundo método (padronizado de precipitação modificado), ao incorporar à mediana, em virtude da assimetria, essa correção resultou na melhoria desse método, quando se compara os resultados entre si.

O método dos Decis integra-se as chances probabilísticas empíricas, para séries climatológicas de chuvas, ordenando-as e dividindo-as simetricamente, em dez partes iguais, ou seja, em décimos.

O primeiro decil, o de menor valor, tem $10 \%$ de chance de ocorrer e assim sucessivamente. As categorias de umidade/seca meteorológica são quantificadas mediantes frequências relativas, com repetições de anos, como mostram a Figura 9.

Figura 9 - Frequências relativas de anos, com categorias de umidade/seca meteorológica, estabelecidas pelo método do Decis. Campina Grande, PB, no período: 1960 a 2020.

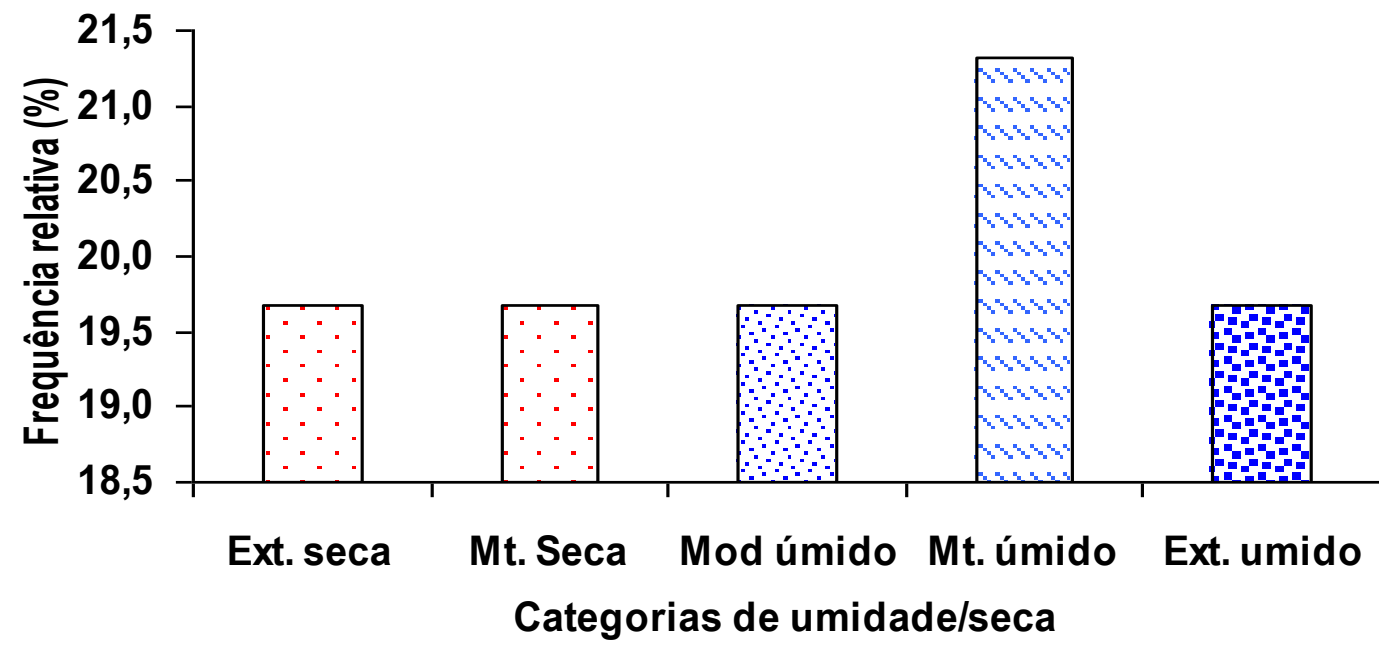


Como se observa na Figura 9, 39,3\% dos eventos de chuvas, enquadra-se nas categorias de extremamente seca ou muita seca, equivalentes aos decis com probabilidade entre 10 e $20 \%$ e 20 e $40 \%$, respectivamente. Já, as categorias moderadamente úmidas, muito úmida e extremamente úmida, equivalem a 60,7\% dos anos, ou seja, 37 dos 61 anos analisados.

Como cada método tem procedimento próprio, resulta na descrição de categoria de seca meteorológica distinta. Condição essa que inviabiliza a comparação, mesmo quando a descrição for a mesma, porque os dados e os cálculos diferem entre si. Assim, não há uma única descrição da categoria de seca e nem um único índice que atenda todas as situações. Por isso, devem-se utilizar dois ou mais índices, o que corrobora com os estudos de Almeida e Marques (2021), Almeida (2017), Fernandes et al., (2009), Blain e Brunini (2007), dentre outros.

Outra característica da seca é a não dissociação do contexto social, porque à duração, intensidade e extensão geográfica, reduz a disponibilidade de água e afeta a produção agrícola (WILHITE e GLANTZ, 1987). O uso desses indicadores de avaliação da seca auxilia no monitoramento e na adoção de medidas de convivência, principalmente, no Semiárido, onde esse fenômeno é mais recorrente e as consequências são mais graves, porque a irregularidade no regime pluvial contribui para esse agravamento (DAI, 2011).

O quantitativo anual de chuvas no Semiárido nordestino não seria, a priori, a causa principal da vulnerabilidade e sim, a irregularidade espacial e temporal, especificamente, na curta estação chuvosa, haja vista as chances de ocorrer veranicos ou estiagens.

Como pode ser observada na Figura 3, a estação chuvosa dura cinco meses chovem o equivalente a 70,0 \% do total anual e tem uma dispersão média da ordem de $65,0 \%$ da mediana esperada. Para averiguar se houvera seca meteorológica, nessa época, utilizaram os índices de anomalia da chuva e o padronizado de precipitação modificado, cujas frequências relativas, por categorias de seca, são mostradas nas Figuras 10 e 11. 
Figura 10 - Frequências relativa das categorias de seca meteorológicas, estabelecidas pelo método do índice de anomalia da chuva, na estação chuvosa. Campina Grande, PB, no período: 1960 a 2020

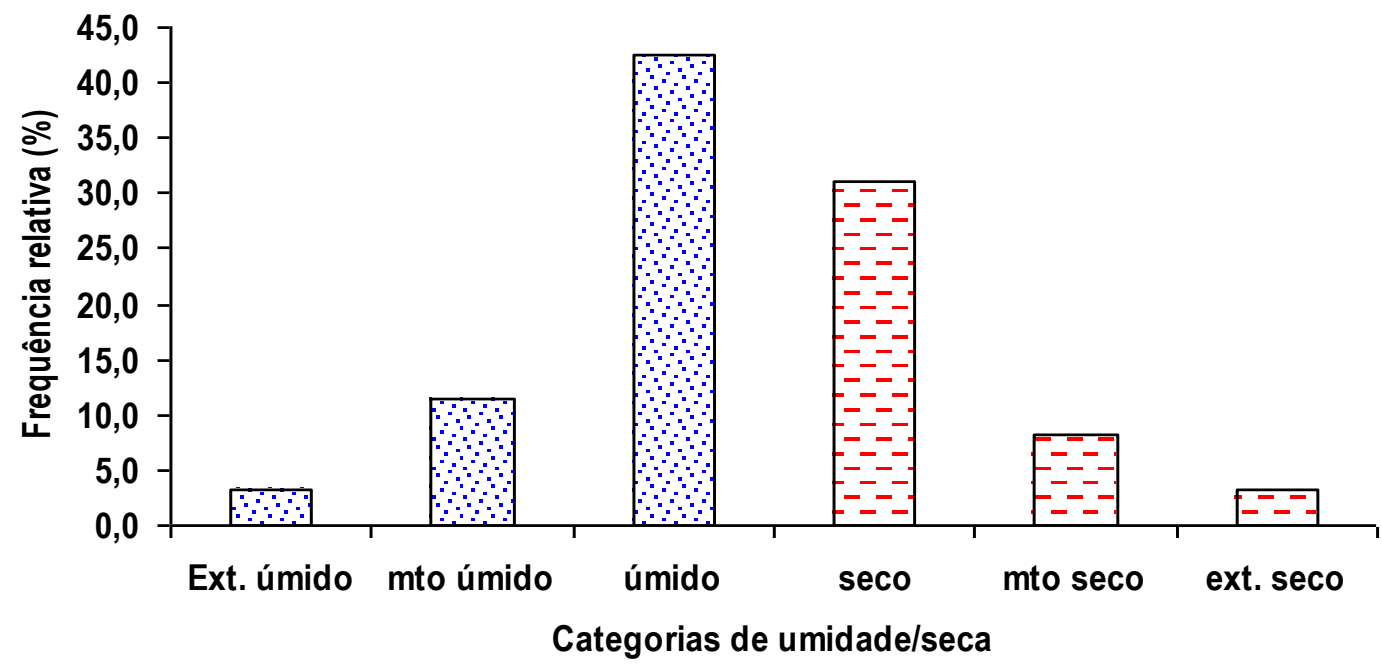

Figura 11 - Frequências relativa das categorias de seca meteorológica, estabelecidas pelo método do índice padronizado de precipitação modificado. Campina Grande, PB, no período: 1960 a 2020.

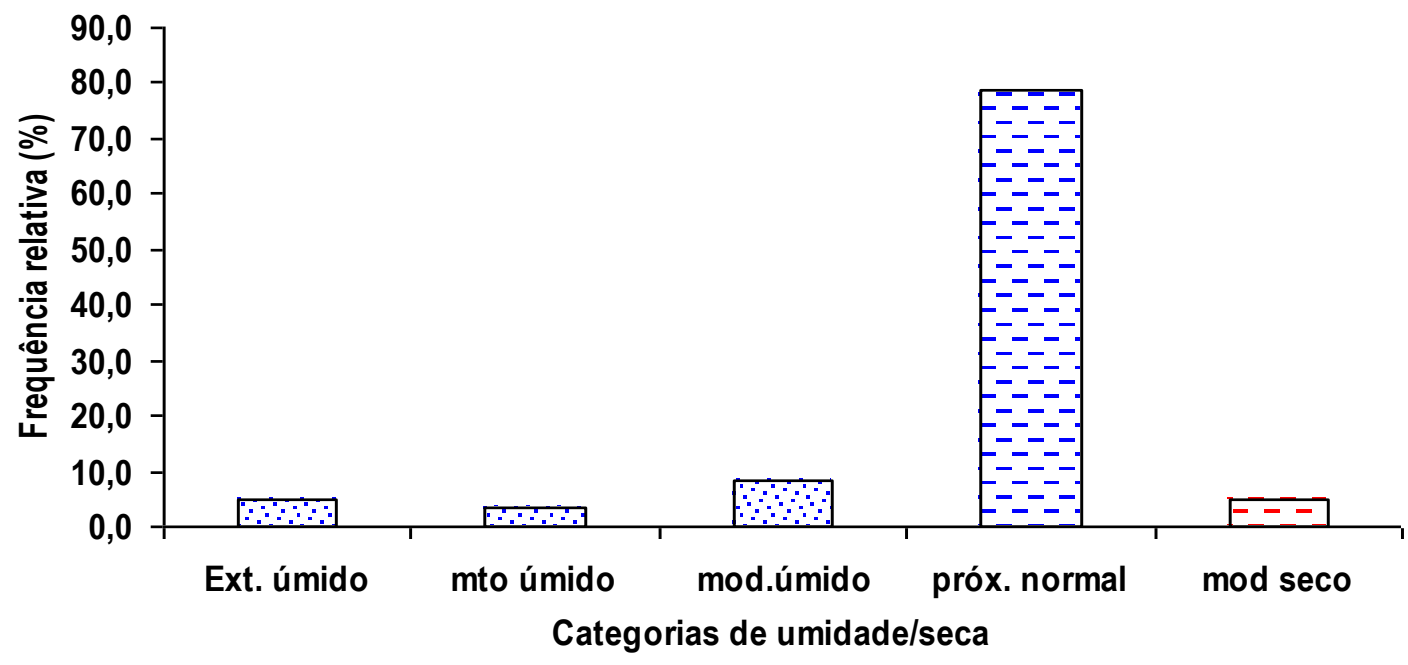

Os percentuais de repetições histogramas, para o método de anomalia da chuva, mostram que as categorias: seco, muito seco e extremamente seco ocorreram em $42,6 \%$ dos anos analisados. Resultados esses que confirmam as chances da estação chuvosa ser seca, o que concorda com Almeida e Ramos (2020), para outras localidades paraibanas. 
Quando se utiliza o índice de seca meteorológica, calculado pelo método padronizado de precipitação modificado, observa-se na Figura 11, a categoria de umidade/seca próxima a normal predominou em 78,7 \% dos anos

Para averiguar se há tendência da estação chuvosa ser seca, contabilizaramse as frequências relativas dos totais observados inferiores ao esperado e comparou-se se essas condições persistiram, cronologicamente, por dois ou mais anos ( $\mathrm{Fr} \geq 2$ anos seguidos), cujos percentuais são apresentados na Figura 12.

Figura 12 - Frequências dos totais de chuvas observados inferiores aos esperados, nos meses da estação chuvosa, e a sequência cronológica de 2 ou mais anos. Campina Grande, PB, no período: 1960 a 2020.

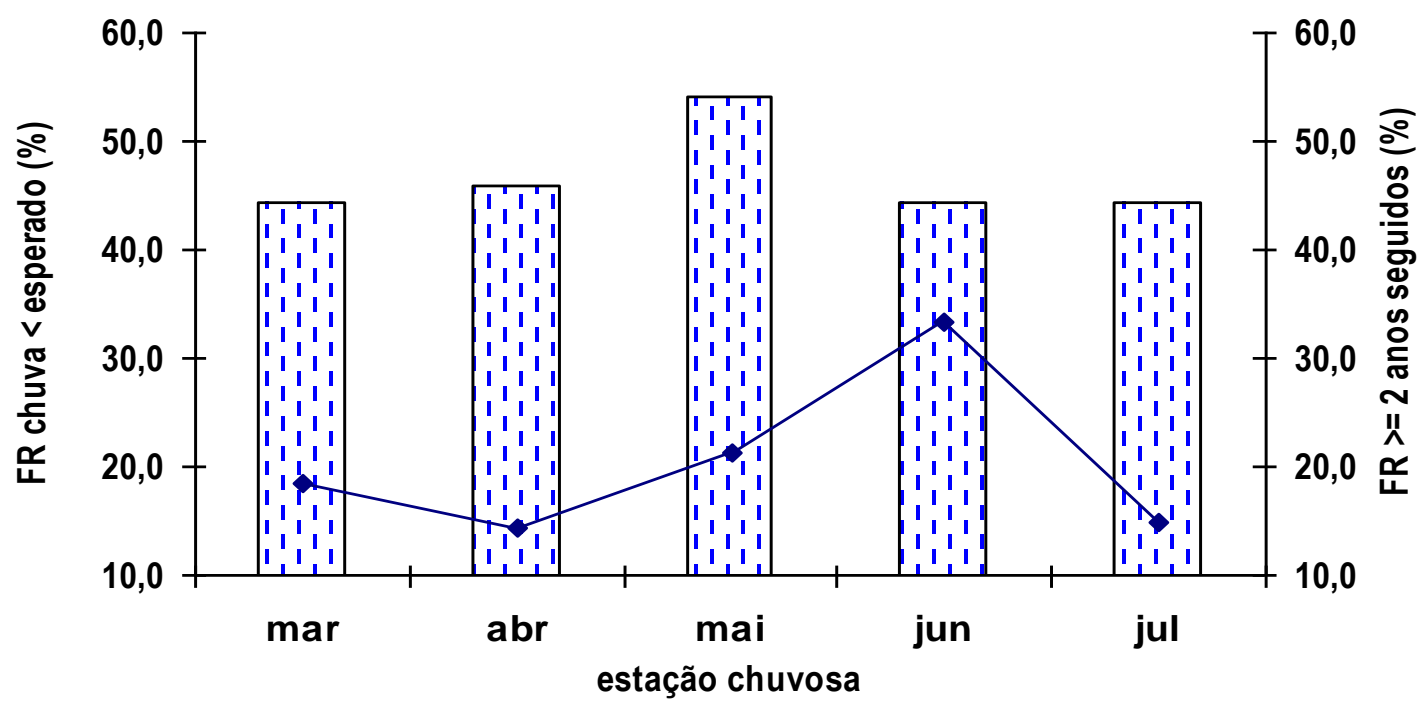

Os elevados percentuais de repetições $(>40,0 \%)$, com totais de chuvas observados durante os meses da chuvosa, nos sessenta e um ano analisados, revelaram, pelo menos, a tendência de chover abaixo do esperado (Figura 12). Além disto, houvera sequência cronológica de dois ou mais anos com essa mesma propensão do regime pluvial.

As análises das características da precipitação pluvial, nos meses da estação chuvosa, baseadas nas categorias de seca, pelos métodos da seca meteorológica, contabilizadas pelas frequência dos totais de chuvas observados inferiores aos esperados são convergentes. Essas condições, conclui-se que a estação chuvosa tem chance de ser 
seca. Resultados esses que concordam com os encontrados para outras localidades por Almeida e Cabral Júnior (2014).

As variabilidades temporais e espaciais da chuva constituem uma característica marcante do clima do Nordeste do Brasil, em particular sobre a porção semiárida, onde a irregularidade temporal e espacial das chuvas constitui fator relevante, até mesmo que os totais pluviais sazonais propriamente ditos.

Destaca-se, ainda, que os índices de seca são técnicas estatísticas que possibilitam identificar, avaliar e monitorar o grau de severidade da seca, o tempo de duração e as diferentes categorias de seca, nas escalas espaciais e temporais, identificando-as os padrões de variabilidade da chuva.

\section{CONCLUSÕES}

Os modelos mensais e anuais de distribuição de chuvas, para a cidade de Campina Grande, PB, são assimétricos, irregulares e as variabilidades são inversamente proporcionais aos valores esperados.

A estação chuvosa é assimétrica, irregular e com chance de ser seca, com destaque para as mais secas as dos anos de 2012 a 2020, por serem enquadradas nas categorias de seca a muito seca.

As oscilações na climatologia da chuva tanto as mensais quanto as anuais são indicativas de variabilidade natural e não há indícios de mudança climática (desse elemento). Os eventos extremos ocorreram em apenas $10 \%$ dos anos e não foram altamente significativos.

O critério da anomalia da chuva (AC) é um método comparativo e efetivo para analisar o modelo de distribuição de chuva local. As anomalias observadas nos totais anuais e na estação chuvosa de Campina Grande revelaram irregularidade no modelo de distribuição, com magnitudes positivas maiores que as negativas.

A seca é uma característica temporária do Tempo e os índices de seca meteorológica (IAC, SPIM e Decis) são importantes para monitorar as diferentes 
categorias de umidade/seca. No entanto, recomenda-se o uso de dois ou mais índices, além da comparação entre si a fim de estabelecer a tipologia da seca

\section{REFERÊNCIAS}

ALMEIDA, H. A, de; MARQUES, M. P. F. Análises comparativas de índices de seca meteorológica para o polo de Petrolina, PE, e Juazeiro, BA. Revista Científica Multidisciplinar Núcleo do Conhecimento, v. 6, pp. 81-98, 2021.

ALMEIDA, H. A. de, SILVA, L. Determinação das características hídricas da microbacia de drenagem da barragem Vaca Brava. Revista Brasileira de Agrometeorologia, v.16, n.1, p.77-86, 2008.

ALMEIDA, H. A. de. Índices de secas e a influência do fenômeno El Niño na estação chuvosa de Ipiaú, BA. Agrotrópica, v.29, n.1, p.51-62, 2017.

ALMEIDA, H. A. de; CABRAL JÚNIOR, J. B. Variabilidades sazonais e interdecadais da chuva nas microrregiões geográficas do estado da Paraíba. Revista Brasileira de Geografia Física, v.7, n.5. p. 846-858, 2014.

ALMEIDA, H. A. de; FARIAS, M. P. Potential for rainwater catchment's as an alternative for human consumption in drier micro-region of the state of Paraiba, Brazil. International Journal of Research in Geography (IJRG), v.1, n.2, p.32-37, 2015.

ALMEIDA, H. A. de; RAMOS, D. B. Alternative of living in the geographical outline of cariri paraibano, Brazil. International Journal of Development Research, v. 10, n.5, p. 35820-35824, 2020.

ARAÚJO, L. E. de. MORAES NETO, J. M. de. SOUSA, F. de A. S. de. Analise climática da bacia do rio Paraíba - Índice de Anomalia de Chuva (IAC). Engenharia Ambiental, Espírito Santo do Pinhal, v. 6, n.3, p. 508-523, 2009.

BLAIN, G. C.; BRUNINI, O. Análise comparativa dos índices de seca de Palmer, Palmer adaptado e índice padronizado de precipitação no Estado de São Paulo. Revista Brasileira de Meteorologia, v.22, p.105- 111, 2007.

CHAN, S. C. Análise de distúrbios ondulatórios de leste sobre o Oceano Atlântico Equatorial Sul. São José dos Campos: INPE, 1990. 89p. Dissertação Mestrado.

COELHO, C. A. S., DENIS, H. F. C., MÁRI, A. F. F. Precipitation diagnostics of an exceptionally dry event in São Paulo, Brazil. Theoretical and Applied Climatology, v.125, p. 1-16, 2015. 
COUTINHO, M. D. L; GAN, M. A.; RAO, V. B. Método objetivo de identificação dos vórtices ciclônicos de altos níveis na região Tropical Sul: validação. Revista Brasileira de Meteorologia, v. 25, p. 311-323, 2010.

DAI, A. Drought under global warming: a review. Wiley Interdisciplinary Reviews: Climate Change, v. 2, p. 45-65, 2011

DIAS, E. C., PENNER, G. C. Equação de chuvas intensas para Abaetetuba-PA: estudo comparativo. Research, Society and Development, v.10, n.4, p. 1-13, 2021.

FERNANDES, D. S., HEINEMANN, A. B., PAZ, R. L., AMORIM, A. O., CARDOSO, A. S. Índices para a quantificação da seca. Santo Antônio de Goiás: Embrapa Arroz e Feijão, 48p., 2009.

FERREIRA, P. S., SOUZA, W. M., SILVA, J. F., GOMES, V.P. Variabilidade espaçotemporal das tendências de precipitação na Mesorregião Sul Cearence e sua relação com as anomalias de TSM. Revista Brasileira de Meteorologia, v.33, p. 141-152, 2018.

GAN, M. A; KOUSKY, V. E: Vórtices ciclônicos da alta troposfera no oceano Atlântico Sul. Revista Brasileira de Meteorologia, v.1, n. 92.651, p. 19-28, 1986.

JUNGES, A. L.; MASSONI, N. T. O Consenso Científico sobre Aquecimento Global Antropogênico: Considerações Históricas e Epistemológicas e Reflexões para o Ensino dessa Temática. Revista Brasileira de Pesquisa em Educação em Ciências, v.18, n.2, p. 455-491, 2018.

KOUADIO, Y.K., SERVAIN, J., MACHADO, L. A. T. LENTINI, C.A.D. Heavy Rainfall Episodes in the Eastern Northeast Brazil Linked to Large-Scale OceanAtmosphere Conditions in the Tropical Atlantic. Advances in Meteorology, v. 2012, 16 p., 2012.

MACHADO, C. C. C., NÓBREGA, R. S, OLIVEIRA, T. H., ALVES, K. M. A. S. Distúrbio Ondulatório de Leste como Condicionante a Eventos Extremos de Precipitação em Pernambuco. Revista Brasileira de Climatologia, 8, v. 11, 2012

MARENGO, J. A. Água e mudanças climáticas. Estudos Avançados, v.22, n.63, p. 8396, 2008.

MARENGO, J. A.; CUNHA, A. P.; ALVES, L. M. A seca de 2012-15 no semiárido do Nordeste do Brasil no contexto histórico. Climanálise, v. 3, p. 49-54, 2016.

MCKEE, T. B.; DOESKEN, N. J.; KLEIST, J. The relationship of drought frequency and duration to the time scales. In: CONFERENCE ON APPLIED CLIMATOLOGY, 8, 1993, Anhaeim, CA. Proceedings. Boston: American Meteorological Society, p. 179184, 1993. 
MOLION, L. C. B; BERNARDO, S. O. Dinâmica das chuvas no nordeste brasileiro. Congresso Brasileiro de Meteorologia, p.1334-1342, 2000.

NOBRE, C. A., MOLION, L.C.B. The climatology of droughts and drought prediction. The Impact of Climatic Variations on Agriculture. Assessments in Semi-Arid Regions, M. Parry, T. R. Carter, and N. T. Konijn, Eds., Kluwer Academic, p. 305-323, 1988.

OLIVEIRA, G. C. S.; NÓBREGA, R. S.; ALMEIDA, H. A. de. Perfil socioambiental e estimativa do potencial para a captação de água da chuva em catolé de casinhas, PE. Revista de Geografia (UFPE), v. 29, no. 1, p. 75-90, 2012.

PALMER, W. C. Meteorological drought. US Weather Bureau Res. No 45. Washington, $58 \mathrm{p}, 1965$.

PINA, A., SILVA, L. F., OLIVEIRA JÚNIOR, Z. T. Mudanças climáticas: reflexões para subsidiar esta discussão em aulas de física. Caderno Brasileiro de Ensino de Física, v.27, n.3, p. 449-472, 2010.

REBOITA, M. S.; GAN, M. A., ROCHA, R. P.; AMBRIZZI, T. Regimes de precipitação na América do Sul: uma revisão bibliográfica. Revista Brasileira de Meteorologia, v.25, n.2, $185-204,2010$.

SILVA, A.; SANTO, F.; PIRES, V. A Seca em Portugal: Prevenção, Monitorização e Mitigação. Lisboa: Fundação Calouste. Gulbenkian, 128 p, 2005.

UVO, C. A Zona de Convergência e sua relação com a precipitação no Nordeste Brasileiro. São José dos Campos. 120 p. (INPE-4887-TDL/378). Dissertação de Mestrado. Instituto Nacional de Pesquisas Espaciais-INPE. 1989.

WILHITE, D. A.; GLANTZ, M. H. Understanding the drought phenomenon: The role of definitions. In: WILHITE et al. Planning for drought toward a reduction of societal vulnerability. WESTVIEW, p.11-14, 1987. 